\title{
SUR JOVELLANOS ET CAMPOMANES
}

Traditionnellement, c'est à partir de 1778 , lorsque Jovellanos arrive à Madrid pour prendre ses fonctions d'Alcalde de Casa y Corte, que ses biographes signalent ses relations avec Campomanes. A cette date, Jovellanos a 34 ans et Campomanes 55.

Ces rapports--souligne-t-on-, sont excellents. Jovellanos se montre plein d'admiration et de respect pour le Procureur du Conseil qui est pour lui non seulement un Mentor, mais un modèle; et Campomanes de son côté fait jouer son prestige et sa puissance au profit de son jeune compatriote-l'un et l'autre sont asturiens-, pour l'aider à faire sa place dans la Société madrilène. Il lui sert même à l'occasion de parrain: “Peu après son arrivée à Madrid, Jovellanos, sur proposition du Comte de Campomanes, fut élu à l'Académie de l'Histoires' ${ }^{1}$.

Le nouveau madrilène relate qu'il participait assidument à la "tertulia» qui se tenait chez Campomanes ${ }^{2}$. C'est là notamment qu'il fit la connaissance de Cabarrús, dont la vivacité d'esprit et la forte personnalité l'attirèrent aussitôt, et dont il devait comme l'on sait devenir l'ami. A ces réunions apparaissait fréquemment la soeur cadette de l'Alcalde de Casa y Corte, Josepha, plus connue sous le nom de "La Argandona", car elle avait épousé D. Domingo González de Argandona, qui représentait à Madrid les intérêts du Principat des Asturies.

Les relations entre les deux économistes furent donc bonnes, et même assez étroites apparemment, durant plus d'une décennie, de 1778 à 1790 Comme ils se voyaient alors fréquemment et pouvaient traiter de vive-voix

(1) B.A.E., t. 46, pág. XIV.

(2) Somoza, Documentos, II, p. 415 et 476. 
les problèmes qui les intéressaient, on conçoit que la correspondance qu'ils auraient pu échanger durant ces années ait été peu active. Il n'est done pas surprenant de n'en point trouver trace parmi les documents qui nous sont parvenus.

On sait comment, au cours de l'été 1790 , les accusations portées contre Cabarrús, et les persécutions dont elles furent le prélude, amenèrent Jovellanos alors en mission à Salamanque, à revenir brusquement à Madrid pour défendre son ami calomnié. Entre le 22 et le 27 août, il multiplia les démarches, les entrevues, les plaidoyers. Campomanes ayant refusé de le recevoir, Jovellanos Iui adresse une letre extrêmement vive, voire cinglante sous son exquise courtoisie de forme, à laquelle Campomanes ne voulut pas répondre par écrit. Il fit simplement dire à Jovellanos qu'il ne pouvait lui accorder un entretien, que son initiative et ses démarches étaient dangereuses pour lui et pour les autres; qu'il était toujours son ami, mais qu'il ne pouvait rien faire pour aider Cabarrús ${ }^{3}$.

Cet épisode eut de sérieuses répercussions sur les relations entre les deux hommes. Profondément déçu par l'attitude de celui qu'il considérait comme son maître-"vous voulez être héroïque, avait dit Campomanes, moi je ne puis l'être»-, Jovellanos, sans jamais manquer aux apparences du respect, va prendre ses distances vis-à-vis de son aîné, dont la faiblesse de caractère l'a choqué. Dès lors les rapports se distendent. S'il est vrai qu'il y a encore échange de quelques lettres, d'affaires ou de courtoisie surtout, on constate que Campomanes est très rarement cité-quatre fois-dans les Diarios de Jovellanos, entre 1791 et 1802 , et ces références sont quasi accidentelles. D'ailleurs, depuis 1791, le Procureur du Conseil a renoncé à la gestion des affaires publiques, et obtenu du Roi l'autorisation de se retirer. Il mourra 12 ans plus tard, le 3 février 1802 .

Mais avant 1778 , ne savons-nous vraiment rien des rapports entre les deux asturiens?

Angel del Río note que pour Jovellanos Campomanes «avait été autrefois un maître et un ami». Cet (autrefois semble bien nous reporter aux

(3) Sur cette affaire complexe, le début du premier Diario de Jovellanos, bien que d'interprétation difficile en ce qui concerne certains détails, apporte bien des lumières. 
années qui nous intéressent ici et sur lesquelles nous ne possédons qu'un document: la Carta al Ilustrísimo Sr. D. Pedro Rodríguez Campomanes, sobre el proyecto de Erarios públicos ${ }^{4}$, que I'on date à la suite de Ceán du 6 août 1777. Mais la formule initiale de politesse «Hlustrísimo Señor; Señor», aussi banale qu'impersonnelle, laisse croire que Jovellanos à cette époque ne connaissait que de nom, ou de renom, le destinataire de son étude. Le fait est d'autant plus curieux que ce n'est point la formule qu'il emploie habituellement dans sa correspondance avec le Fiscal durant ces années-là. D'autre part le jeune magistrat, dans cette analyse sérieuse et fouillée, cherche évidemment à briller par ses connaissances d'économiste et à s'attirer les bonnes grâces de Campomanes auquel il rend un signalé service en lui fournissant un ouvrage qu'il regrettait de n'avoir pu consulter. De cette pièce officielle, technique, un peu ésotérique et assez guindée, nous ne pouvons donc tirer aucune indication nouvelle sur les rapports qui unissaient les deux hommes.

Il en va tout autrement de certaines lettres qu'il nous a été donné de lire récemment ${ }^{5}$. Elles sont au nombre de onze, sans compter trois postscripta intéressants. Une seule se trouve dans le fonds Carmen Dorado, déposé depuis quelques mois à la Fondation Universitaire Espagnole. Les dix autres procèdent d'archives particulières. Cette correspondance s'étale sur 29 ans, de 1768 à 1797 , mais avec un blanc total correspondant aux années 1778-1790, que nous avons déjà évoquées, et pendant lesquelles Jovellanos, vivant à Madrid, était en contact quotidien avec Campomanes. Sept d'entre elles, dont une déjà publiée, encore qu'avec une date erronée et amputée de son post-scriptum, furent écrites à Séville entre 1768 et 1777. Les trois autres sont datées de Salamanque en 1790 et de l'Escorial et Madrid en 1797.

De l'aveu même de Jovellanos, celui-ci aurait adressé en outre à Campomanes une lettre (peut-être deux), entre le 30 mars et le 25 juillet 1768 , dont le texte n'a pas été retrouvé jusqu'ici. Au total, en incluant dans ce décompte la fameuse lettre du 24 août 1790, nous connaissons donc l'exis-

(4) Publiée dans le B.A.E., 50, p. 139-143.

(5) A la Fondation Universitaire Espagnole, où Madame Carmen Dorado, héritière d'une partie des archives de Campomanes, a eu la généreuse initiative de déposer ces documents que peuvent consulter les chercheurs. Par ailleurs nous avons eu accès à d'autres archives privées, où étaient conservées plusieurs pièces intéressantes. (Fonds Rafael Gasset Dorado). Nous remercions très vivement les propiétaires de ces manuscrits, de nous avoir autorisé à les consulter. 
tence de 13 lettres de Jovellanos à Campomanes, et possédons le texte de 12 d'entre elles. Il en existe certainement beaucoup d'autres ${ }^{6}$.

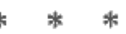

Ce qui frappe avant tout dans cette correspondance, c'est le ton. Même dans les toutes premières missives, qui sont de 1768 , il diffère très sensiblement $\mathrm{du}$ ton froid et impersonnel qui caractérisait la lettre sur le Proyecto de Erarios públicos, rédigée dix ans plus tard.

Non seulement nous avons la preuve que, dès 1768, les deux asturiens se connaissaient, mais nous pouvons ajouter qu'à cette époque on décèle chez Jovellanos une respectueuse familiarité à l'égard de Campomanes. Le Gijonnais est certainement entré en rapport avec le Procureur du Conseil lorsque, ayant abandonné la carrière ecclésiastique, il attend à Madrid, modeste solliciteur, que le Roi lui accorde un emploi. Campomanes a dû lui fournix alors une aide efficace, voire décisive, ce qui explique les formules “Muy Señor mío y mi venerado favorecedor», «mi favorecedor y mi dueño», (mi estimado favorecedor», par lesquelles Jovellanos commence ses missives. C'est là un qualificatif dont il usera toujours, et jusque dans les moments de plus grande tensión motivée par l'affaire Cabarrús. D'ailleurs le premier document que nous reproduisons ne laisse place à aucun doute: le jeune magistrat exprime sa reconnaissance "pour le poste que je dois principalement à votre faveur», et ce mot de (favor» revient avec insistance dans la missive.

Le ton de cette lettre, parfaitement courtois et déférent, mais empreint de familiarité et de liberté, semble donc démontrer que dès 1768 s'étaient établies entre Jovellanos et Campomanes de cordiales relations; le jeune solliciteur ne s'était pas borné à faire une visite officielle au Procureur du Conseil de Castille; il avait certainement été reçu chez Campomanes, sur un plan amical, voire familial. C'est ainsi qu'il avait fait connaissance de la comtesse, "D. Manuela», de ses filles, "las señoritas», et de leur frère, Sabino. Enfin, la commission, si non la mission, dont l'avait chargé le Comte de lui communiquer toute nouvelle de quelque intérêt, et la façon dont le jeune homme s'acquitte de cette tâche, en formulant un jugement très libre,

(6) Ajoutons que les archives consultées nous ont fourni également le texte de deux lettres de Camponanes à Jovellanos, l'une du 21 mai 1786 (relative à des questions de bibliographie), l'autre du 9 mars 1798, simple billet de remerciement en réponse à la lettre de Jovellanos du 25 novembre 1797. 
encore que bienveillant, sur le Régent de l'Audience de Séville, nous apportent la preuve de l'existence entre les deux hommes de relations directes et confiantes.

C'est pourquoi il est permis d'inférer que le moment où Jovellanos a été présenté au Procureur est nettement antérieur à l'année 1767. Peut-être ce premier contact eut-il lieu alors que Jovellanos séjournait à Avila, ou mieux à Alcalá. Il est vraisemblable en effet que le brillant étudiant du Colegio Mayor de San Ildefonso ait été conduit chez le Comte par quelqu'un de ses parents qui résidaient alors à Madrid, soit son oncle le Due de Losada, Grand Chambellan de Sa Majesté, ou ses cousins, Marquis de Casa Tremañes. Nous inclinerions à croire que c'est entre 1763 et 1766, que Jovellanos fit la connaissance de D. Pedro et de sa famille.

Bien que les lettres à Campomanes soient très disparates du fait même de leur éparpillement au long de trente années - Jovellanos signe la première comme magistrat débutant et la dernière comme Ministre de la Justice-, on peut grouper sous six rubriques les sujets dont elles traitent ${ }^{\text {? }}$.

A. Le courtisan - Jovellanos félicite le Procureur pour la pensión que le Roi vient de lui accorder ãinsi qu'à ses filles (Lettre n. ${ }^{\circ} 2$ ). Il l'incite courtoisement à faire sans plus attendre benéficier le pays de son Discours sur l'Agriculture $\left(n \cdot{ }^{\circ} 8\right)$; enfin il le remercie des félicitations qu'il lui a adressées lors de son élévation au Ministère $\left(n .^{\circ} 12\right)$.

B. Le solliciteur - Plussieurs des lettres que nous publions nous montrent un Jovellanos qui ne craint pas de réclamer des avantages ou des faveurs.

Pour lui-même, d'abord. On sait qu'il avait été nommé ministre criminel (mais seulement avec demi-solde» ${ }^{8}$. Il rappelle à son correspondant «la miseria del medio sueldo» ( ${ }^{\circ} 2$ ). Et en 1770 , il n'hésite pas à solliciter une (commission» qui lui permettrait de donner la preuve de ses talents, et de percevoir un supplément de traitement $\left(n .^{\circ} 3\right)$.

En vérité, si Jovellanos apparaît à plusieurs reprises comme un "pretendienten, e'est souvent en faveur d'autrui. Il réclame une prébende ou un canonicat pour son ami D. Josef Tabera, ecclésiastique de grand mérite, qui

(7) Nous désignons ces lettres par le n. ${ }^{\circ}$ qu'elles portent dans le tableau chronologique qui précède le texte de cette correspondance (voir ci après page 44).

(8) Ceán, Memorias, 1. ${ }^{\mathrm{a}}$ parte, cap. 4. 
n'a pour vivre, lui aussi, qu'une «demi-ration» ( $\left.n^{\circ} 5\right)$. Il recommande son ami Ceán Bermúdez, non point tant pour lui faire attribuer une aide pécuniaire que pour obtenir son admission dans l'atelier de Mengs. Sa requête pleine de détails précis, est extrêmement instructive et intéressante $\left(n^{\circ} 6\right)$. Enfin, une lettre, sậs lieu ni date, mais très probablement de la période sévillane, et qu'il seræ sans doute possible de dater par référence, a trait à une recommandation faite par Campomanes sur les instances de Jovellanos en faveur d'un certain Peláez, recommandation qui n'a pas produit l'effet escompté (no 9$)$.

C. Le partisan des idées éclairées - Sous ce titre on pourrait regrouper plusieurs paragraphes ayant trait à diverses enquêtes ou initiatives du magistrat en faveur de certaines écoles ( $n^{\circ} 4$ et 10), et à son action comme Ami du Pays ( $\mathrm{n}^{\circ}$ 5, 7 (en post-scriptum) et 10).

D. Le paladin de l'amitié, que l'on a déjà vu à l'oeuvre en d'autres occasions (voir ci-dessus $\S \mathrm{B}$ ), vante à Campomanes les mérites du Régent Cárdenas (n. 2). Ceán nous apprend que D. Luis de Cárdenas y Montalvo, ancien élève du Colegio Mayor de San Ildefonso, comme Jovellanos, entretenait avec celui-ci les meilleures relations: "Ya le tenía casa aparejada su colegial Cárdenas, Regente de aquella audiencia) ${ }^{9}$. Le témoignage de Jove. llanos sur ce magistrat ne pouvait done être que bienveillant.

Nous ne mentionnerons que pour mémoire, la lettre déjà citée de Jovellanos à Campomanes sur son amitié avec Cabarrús (24.VIII.1790). C'est un document fier et généreux qu'il faut relire $\left(\mathrm{n}^{\circ} 11\right)$. On y voit comment l'asturien et déchiré entre deux amitiés. Et l'amitié pour lui est chose sacrée.

E. Le Théoricien de l'Economie et l'Erudit: (n." 7 et 8).

F. Le Ministre de la Justice, enfin (n.* 13).

Telles quelles sont, ces lettres, dont on peut déplorer le nombre réduit, sont significatives. Elles jettent un jour nouveau sur la période sévillane, sans doute encore la moins connue de la vie de Jovino. Elles nous apportent une preuve supplémentaire de la grande curiosité d'esprit du jeune Ministre Criminel ou de l'Oidor de l'Audiencia et des multiples intérêts autour

(9) Céá, Memorias, 2.a parte, eap. 40. 
desquels se cristallisait son activité multiforme. Elles nous montrent aussi ses qualités humaines, son dévouement pour les nobles causes, et son adhésion agissante aux idées de l'lllustration. D'autre part, elles permettent de mieux situer dans le temps, et de saisir de façon plus nuancée les relations de disciple à maître, puis de jeune à ancien magistrat, qui débouchèrent sur une véritable amitié entre les deux Asturiens. Replacée dans ce contexte, la mémorable missive déjà citée du 24 août 1790 , avec sa parfaite courtoisie de forme, et sa bouillante indignation mal contenue, prend une dimension véritablement dramatique.

Ces lettres ont encore un autre mérite, extrinsèque il est vrai. Simples échantillons des richesses documentaires que contiennent les archives soigneusement conservées de Campomanes, elles nous permettent d'espérer que lorsque ces fonds, divisés, seront reconstitués et ouverts au public, les chercheurs y trouveront ample matière à des études susceptibles de changer sensiblement l'image que l'on se fait des deux économistes les plus marquants du XVIIIle siècle espagnol.

Georges Demerson 


\section{TABLEAU DE LA CORRESPONDANCE CONNUE A CE JOUR DE JOVELLANOS ET CAMPOMANES sauf erreurs ou omissions}

\section{Lettres de Jovellanos à Campomanes.}

\begin{tabular}{|c|c|c|c|c|c|}
\hline Sevilla & \multicolumn{2}{|c|}{30 mars -23 juillet 68} & \multirow{2}{*}{\multicolumn{3}{|c|}{$\begin{array}{l}\text { (une ou deux lettres) }{ }^{10} \\
\text { Fonds Rafael Gasset Do }\end{array}$}} \\
\hline (2) & 23 juillet & 1768 & & & \\
\hline (3) & 7 mars & 1770 & $n$ & $»$ & 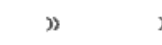 \\
\hline (4) & 12 juillet & 1775 & 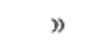 & ” & $»$ \\
\hline (5) & $17 \mathrm{mai}$ & 1776 & $n$ & $»$ & ” \\
\hline (6) & 1 août & 1776 & ” & $»$ & $»$ \\
\hline (7) & 6 septembre & $1777^{11}$ & $"$ & $»$ & $"$ \\
\hline (8) & 31 octobre & 1777 & 》) & 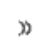 & $\eta$ \\
\hline [S. 1.] & [s. a.] & & $"$ & $"$ & $"$ \\
\hline Salamanaca & 13 avril & 1790 & ” & $n$ & » \\
\hline Madrid & 24 août & $1790^{12}$ & $"$ & $"$ & $n$ \\
\hline San Lorenzo & 25 novembre & 1797 & ” & " & 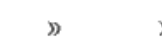 \\
\hline (13) Palais Royal & 20 décembre & 1797 & $\begin{array}{l}\text { Fond } \\
\text { pagn } \\
\text { Fond }\end{array}$ & Carn & $\begin{array}{l}\text { niversitaire } \\
\text { n Dorado. }\end{array}$ \\
\hline Lettres de $C$ & npomanes à $J$ & ovellanos. & & & \\
\hline Madrid & $21 \mathrm{mai}$ & 1786 & Fond & $\operatorname{arm}$ & n Dorado. \\
\hline » & 9 mars & 1798 & & & \\
\hline
\end{tabular}

(10) Voir lettre du 23.VII.68 (ler §) Nous ignorons où se trouvent ces lettres ou cette lettre.

(11) B.A.E., 50, p. 139. Ceán avait indiqué que cette lettre était du 6 août 1777. Le manuscrit montre qu'il se trompait d'un mois.

(12) B.A.E., 86, p. 168. 
Muy Sr. mio y mi venerado favorecedor:

Después que participé a V. S. mi arribo a esta ciudad, y mis primeros establecimientos en el destino que debo principalmente al favor de V. S., no he querido repetir carta alguna por no usurpar a V.S. el tiempo que tan dignamente destina al desempeño de sus gravisimas ocupaciones. Pero habiéndome avisado Argandona que S. M. había señalado a V. S. y a las señoritas tres pensiones, he resuelto significar a V.S. la singular complacencia que me ha causado esta noticia, que aunque se deba suponer en el agradecimiento en que me constituyen los favores con que V. S. me ha distinguido, no excuso el hacerlo presente por que no se confunda la verdadera fineza con que miro las proporciones de esa casa en el olvido de este necesario silencio.

Tengo carta del Tío Sumiller los más correos; en el favor de V. S., el patrocinio de este poderoso y el esmero con que dedico mi corto talento al desempeño de las obligaciones de juez criminal, confio que algún día podré salir de la miseria del medio sueldo. La renta es poca, el pueblo lucido, las casas y los alimentos carísimos, la decencia en un juez indispensable, de suerte que ni aun a costa de andar a pie puedo lograr el estar bien sustentado.

V. S. me ha dado facultad para que le representase humildemente lo que creyese digno de su noticia. En este supuesto, no puedo dejar de acordarle que nuestro Regente, el Sr. Cárdenas, es un buen letrado, un juez integro, un sujeto que ha servido a $S$. M. con mucho celo y honor y finalmente digno de que no se quede Regente perpetuo, y de que se le proporcione algún ascenso.

Quedo con el más fino rendimiento a los pies de mi Señora Doña Manuela y señoritas, y deseoso de que $V$. S. mande cuanto quiera a su favorecido y más reconocido servidor que B. L. M. de V.S.

$$
\text { Gaspar de Jovellanos }
$$

Sevilla, hoy 23 de julio de $1768^{13}$.

(13) 2 pliegos en 4..5; autógrafa. 
Muy Sr. mío, mi favorecedor y mi dueño:

Dos años ha que excuso a V.S. la molestia de mis cartas, y continuaria por más tiempo este silencio, si no me obligase a interrumpirlo mi necesidad. Actualmente estoy pagando el último año de media anata, habiendo estado uno con medio sueldo, y creo que esta consideración y el notorio desinterés con que he procedido, bastaban a disculpar la solicitud del día.

Mi hermano, D. Domingo Argandona, tiene el encargo de hacer presente a V. S. que si hubiese lugar de proporcionarme algún encargo o comisión del Consejo, podría recordar V. S. mi nombre para él. Yo lograría a un mismo tiempo tener alguna ayuda de costa y dar a conocer mi ardiente deseo de servir a S. M. y contemplando que una residencia podría ser encargo proporcionado a mis fuerzas, espero que V.S. le ayude con su influjo al logro de esta solicitud. En todos casos, la aprobación debe preceder a cualquiera diligencia que haga a mi favor, y el de $V$. S. es el único que podrá esforzarla. Así lo espero de su piadosa benignidad a que viviré siempre agradecido.

Dios N. S. guarde a V.S. muchos años.

Gaspar de Jovellanos

Sevilla, 7 de marzo de $1770^{14}$

[12 julio 1775]

Muy Sr. mío y mi favorecedor:

En el correo de hoy se dirige al Supremo Consejo extraordinario un informe que yo he hecho por encargo de la Junta municipal de Temporalidades de esta Ciudad sobre el patronato de ciertas escuelas que deben establecerse en ella, y se dejó por la fundadora a los Jesuitas.

Como esta institución, bien establecida, será tan conforme a las ideas que V.S. I. expone en su sabio Discurso sobre la educación popular y puede producir al público las mayores utilidades, me ha parecido adelantar a $V$. S. I. esta noticia para que cuando llegue este expediente a sus manos

(14) Autógrafa - 1 pliego en $4 .^{\circ}$ 
se digne mirarle con la atención que merece, en el supuesto de que sólo con la vista del informe penetrará $V$. S. I. hasta dónde puede interesarle la enseñanza pública de esta Ciudad, si se diese a tan saludable establecimiento una forma ilustrada y constante. Con este motivo, me repito a la disposición de V.S. I., y ruego a N. Sr. guarde su importante vida muchos años.

Sevilla y Julio 12 de 1775.

Gaspar de Jovellanos

P. D. Nadie puede leer la fundación de que habla nuestro informe sin interesarse muy de veras en un establecimiento que sólo sabrán apreciar justamente los que conozcan como V.S. I. la suma de las utilidades que produce una buena educación. Esto solo me ha movido a molestar la atención de V. S. I. con esta carta, para anticiparle una noticia tan conforme a sus ideas ilustradas ${ }^{15}$.

[17 mayo 1776]

Muy Sr. mío y mi venerado favorecedor:

Como sé que V.S. es protector declarado de los hombres de mérito, he resuelto recomendarle el de Don Josef Tabera, prebendado de esta santa Iglesia y persona que reúne a todas las virtudes sacerdotales un ingenio sobresaliente y delicado, una erudición vasta y escogida. Reducido a vivir de una media ración en este país donde el alimento y vestuario se compran a precios altísimos, está precisado a pasar una vida oscura con tanto retiro y estrechez que sólo pudieran hacerla tolerable su parsimonia y su recogimiento. Yo le conozco muy bien, y aseguro a V.S. I. con ingenuidad que me compadece el verle adocenado en las tiltimas sillas de su coro cuando las buenas calidades y dotes que posee le hacen acreedor a las primeras. Es uno de los cuarenta individuos de la Sociedad Patriótica, que acaba de erigirse en esta Ciudad, como primer fruto del inmortal discurso que V. S. I. ha publicado sobre el fomento de la industria popular, y puedo asegurar que es una de las personas sobre cuyos conocimientos, celo y aplicación funda la Sociedad sus mejores esperanzas. Pero ‘cómo podrá dedicarse todo a este

(15) Amanuense. Letra muy clara. La P. D. es autógrafa. 1 pliego en $40^{\circ}$. 
objeto, distraído por los cuidados que causa la indigencia; crea V. S. I. que tenía mucha razón el célebre consejero de Santa Clara cuando decía:

Is qui res angusta domi est qui paupere stringitur officio par nequit esse suo, sorte gravi afficitur nusquam mens libera curis...

Con este motivo, renuevo a V. S. I. la memoria de mi gratitud, y pido a N. ${ }^{\circ}$ Sr. dilate su vida por muchos años.

\author{
Gaspar de Jovellanos \\ Sevilla, y mayo 17 de $1776^{16}$.
}

P. D.

Ilmo. Sr.:

D. Josef Tavera, desea el logro de la canongia vacante en esta Catedral, no por ambición, sino para vivir con más desahogo y menos estrechez. Sabe $V$. S. I. que no soy importuno y que, hecho cargo de sus graves ocupaciones, no acostumbro distraerle de ellas con súplicas molestas. Pero como sé que V.S.I. desea conocer el mérito dondequiera que esté, y recompensarlo, aunque se halle desvalido, creo que no podrá reprobar este movimiento de mi amistad y amor a la justicia en favor de una persona que merece por mil títulos la protección de $V$. S. I., de quien quedo como siempre muy reconocido y afecto servidor que b. s. $\mathrm{m}$.

$$
\text { G. D. J. }
$$

[Sevilla, y mayo 17 de 1776.]

\title{
[Sevilla $1 .^{\circ}$ agosto de 1776]
}

Muy Sr. mío y mi favorecedor:

Entregará a V. S. la presente D. Juan Ceán Bermúdez, profesor del noble arte de la Pintura que después de unos buenos principios tomados en la Academia de esta Ciudad, pasa a la Corte para perfeccionarse en ellos. Muchos años ha que conociendo yo su aplicación y el sobresaliente genio de

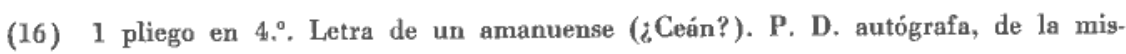
ma tinta, 
que lo dotó la Providencia para aquel arte, habia formado el designio de enviarle a Roma, convencido de que éste era el camino más breve y más seguro de que llegase a perfeccionarse. Pero como nunca correspondieron mis facultades a mis deseos, fue necesario que me conformase con otro pensamiento, si no tan útil ni tan conforme con mis ideas, al menos más proporcionado a los auxilios que puedo darle.

Con efecto, le envío ahora a la Corte con las precisas asistencias parai su decente porte y manutención. Pero nada habré conseguido si las personas aficionadas a las artes y a quienes yo debo el favor que a $V$. I. no me ayudan al cumplimiento de mi designio.

Deseaba yo colocarle al lado del Sr. Mengs, ya fuese en calidad de discípulo o aprendiz, o ya en la de aficionado, de manera que aquel célebre profesor en que fía España la restauración del buen gusto en la Pintura, se encargase de dirigirle, instruirle, corregirle, permitiéndole copiar sus obras, observar la ejecución de ellas, y teniéndole con asiduidad a su lado, inspirándole sus conocimientos y ser su maestro. Para esto me valgo del favor de $V$. S. a quien no haré presente que me ha servido doce años, que ha nacido en el Principado de Asturias, ni que estoy encargado de su fortuna, si no solamente que es profesor de un arte que V. S. estima y protege, que tiene para él un talento nada común, y en fin que promete, por su aplicación $y$ buenos principios, que podrá ser con el tiempo un profesor acreditado.

Como V. S. verá, tiene muy buena figura, muy buen modo, y muy buena crianza; sus costumbres, no sólo son arregladas, sino ejemplares; sus luces y su ingenio de los más despiertos, y en conclusión yo hallo en él todas las cualidades apetecibles; tal vez el cariño que le profeso y el agradecimiento a sus buenos servicios me hacen ponderar sus prendas, pero la estimación de todas las gentes en los pueblos en que ha estado es en su favor un testimonio indefectible. Por todo, lo recomiendo a V.S. con el mayor encarecimiento y me profeso su menor servidor.

Gaspar de Jovellanos

Sevilla, 1. $^{\circ}$ de Agosto de $1776^{17}$.

$* * *$

Chronologiquement, la longue lettre à D. Pedro Rodríguez de Campomanes sur le projet de Banques publiques devrait s'insérer ici. En fait, elle

(17) 1 pliego en $4 \AA^{\circ}$. Autógrafa. 
a été publiée, avec un certain nombre de variantes malencontreuses par rapport au manuscrit du fonds Carmen Dorado, dans le tome 50 de la BAE, page 139.

A la suite du texte, tel qu'il s'achève dans la BAE, p. 143 b, le manuscrit, entièrement dû au copiste, comporte cette phrase:

"Con este motivo, reitero a $V$. S. I. las seguridades de mi reconocida voluntad, y quedo rogando a $N .^{\circ} \mathrm{Sr}$. conserve su importante vida por dilatados años.

Sevilla, 6 de septiembre de 1777.

Gaspar de Jovellanos

Ceán, qui datait cette lettre du 6 août 1777 , se trompait done d'un mois. Mais ce n'est pas tout. Le manuscrit Carmen Dorado comporte un post-scriptum autographe, relatif à la Societé Economique Hispalense, dont le texte est le suivant.

\section{P. D. [autógrafa.]}

Después de escrita ésta, me ha parecido prevenir a V.S.I. que los estatutos de la Sociedad Patriótica de esta Ciudad están muchos meses ha en el Consejo sin haber logrado su aprobación. La brevedad en este despacho sería una prueba de protección que podría dar el Gobierno a este cuerpo a poca costa. De lo contrario se sigue el desaliento de los individuos y la tibieza de el primer fervor sin el cual no puede prosperar ninguna asociación, especialmente si está recién creada.

Suplico a V.S. I. se digne pronunciar una palabra en este asunto para que logre nuestra Sociedad lo que tanto desea.

$[\text { Sevilla, } 6 \text { de septiembre de 1777 }]^{18}$.

(18) En folio. El texto es de letra del amanuense. La P. D. es autógrafa. 
[Sevilla, 31 de octubre de 1777]

Mi estimado favorecedor:

Mientras V.S. continúa enriqueciéndonos con sus obras económicas, creo que le será apreciable la noticia de las que se publicaron en el siglo pasado. Por eso le dirigi el proyecto de Erarios, y por lo mismo paso a sus manos el adjunto impreso. Este documento estaba en un tomo de papeles varios de una librería monacal, y pude redimirle para que ande en manos que sepan apreciarle mejor. Carece de dirección y de firma. Pero el tratamiento de la persona a que se dirige (que tal vez será el Conde-Duque), su fecha, y la expresión final en que dice su autor haber gobernado anteriormente a Toledo, podrían bastar para que $V$. S. que conoce mejor las memorias de aquel tiempo rastree su nombre.

Trae muchas y buenas especies de las más traqueadas entonces, y clama altamente contra los daños causados por los juros y censos a la industria; habla de los vicios de las leyes y administración de Justicia, de los excesos de los eclesiásticos, del crecido número de religiones y religiosos, del fomento de la agricultura y la industria y otros puntos tocados con más tino y conocimiento que otros escritores coetáneos, bien que sus principios no sean siempre conformes a los que ha canonizado la ilustración de los presentes tiempos.

Después de escrita mi carta anterior descubri otra edición del proyecto de los Erarios en 1600, y no la dirigí a V. S. porque me dijo Bruna haberlo hecho. Faltan en la que he visto las oposiciones de D. Juan Centurión y las respuestas de Valle ${ }^{19}$ y Salablanca que acaso habrín sido posteriores. V. S. pues las posee entrambas, podrá apurarlo si acaso conviniese corrigiendo con esta nueva luz lo que yo hubiera dicho equivocadamente en cuanto a la historia del proyecto.

He oído que V. S. tiene acabado el Discurso sobre agricultura que nos ofrece en el de la Industria popular y que difiere su publicación hasta que dé la de todas las obras económicas. Si me fuese licito opinar en esta materia, yo instaría por la pronta publicación de este discurso, pues aunque en todas materias se ignora mucho, no creo que en otra alguna haya tantas preocupaciones ni máximas erróneas como en el ramo de Agricultura y su

(19) Luis Valle de la Cerda, y el Contador Salablanca eran los autores del proyecto de los Erarios, al cual Juan Centurión había hecho algunas objeciones. (véase B. A. E., t. 50, p. $143 \mathrm{~b})$. 
economia con respecto al Gobierno. $Y$ si es verdad que está acabado, es doloroso que se prive de él al público que ha recibido con ansia todas las obras económicas de V.S.

He visto el digno elogio que hace de ellas el sabio doctor Robertson en su nueva Historia de América, y lo tengo puesto en castellano para que vayan viendo mis amigos cómo los extrangeros son los que primero se apresuran para hacer justicia al mérito y loarle doquiera que le encuentran. Quisiera hablar con V. S. de otras mil cosas, pero respeto sus itiles ocupaciones, la delicadeza de las materias, y la miseria de nuestro siglo, y por lo mismo, me contento con repetir a V. S. que soy y seré siempre su más sincero y reconocido apasionado, q. s. m. b.

\section{Gaspar de Jovellanos}

Sevilla, y 31 de octubre de $1777^{20}$.

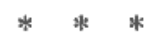

$$
\text { [s. l. s. a. }]
$$

Muy Sr. mío y mi venerado favorecedor:

Al fin se ha perdido la prebenda que recayó en Valcarce; las cartas de V. S. I. hubieran producido todo el efecto que merecían si la inacción en que se mantuvieron los $A m^{\text {ox. }}$ del obispo de Segovia no hubiese dejado tomar fuerzas al partido opuesto y debilitarse el suyo. El logro se hubiera conseguido a poca diligencia de éstos, pero absolutamente no hicieron alguna. Yo miraba con sumo dolor que les arrebataban de las manos esta buena presa. Clamé, insté, y sin embargo se mantuvieron tranquilos y se dejaron vencer. Este es el resumen de todo y lo que V.S. I. debe creer. Pelúez ${ }^{21}$ a la vista tendrá el honor de explicar el pormenor.

En todo caso, él y yo estamos íntimamente reconocidos a las pruebas distinquidas de protección que V.S. I. nos ha dado con este molivo. Y aunque sentimos miny de veras que a sus insinuaciones no se hubiese dado todo

(20) 1 pliego en 4.". Autógrafa.

(21) Ese Peláez, ¡sería acaso D. Felipe Peláez Caunedo, paisano de Jovellanos, y que andando el tiempo, llegaría a ser obispo de Lugo? Obispo poco ilustrado, poco discreto al parecer, a quien Jovellanos escribiría una carta tremenda que concluye así: «Sea Vm. si quiere, ingrato con su patria y desconocido con sus amigos; pero no eaiga otra vez en la tentación de ser desatento con quien pueda tachárselo tan franca $y$ justamente como Jovellanos». 16 diciembre 1799. SomozA, Documentos, t. I, pág. 223-225. 
el aprecio que por tantos títulos merecian, siempre nos quedará el consuelo, a Peláez de haber sido el objeto de ellas, y a mi, de haber merecido que V. S. I. las hiciese a influjo mío.

También nos queda el consuelo de que todos hagan justicia al mérito del Sr. Peláez, manifestado tan sobresalientemente en este caso. La pasión ni el furor de partido no han bastado a oscurecerle y a pesar del ardor con que muchos se declararon por Valcarce, la fuerza de la verdad arrancó a los mismos que le favorecían la confesión del mérito de su rival. Así ha quedado siempre airosa la protección de V.S. I., concedida a un sujeto digno de ella. Lo demás importa poco. Por lo común, en estos casos, ni el Espíritu Santo influye, ni la Razón alumbra, ni la Justicia decide. Cada particular se determina por razones privadas y la voluntad general de una comunidad es siempre el resultado de las inclinaciones particulares.

Repito a V. S. I. las más rendidas gracias por la continuación de su favor, y quedo deseoso de sus preceptos, rogando al Altísimo conserve feliz su persona por $m^{s}$. $a^{s}$.

De V.S. I. el más reconocido y fino servidor,

\section{Gaspar de Jovellanos}

P. D. En un catálogo de libros italianos que estoy reconociendo, se halla el siguiente: "La Causa de Poveri Superiore agli ornamenti meno utili, ̀̀ superflui dell' altare, opera attribuita al célebre Campomanes, 1767 , en $4 .^{\circ}$. Si V.S. I. lo tuviere a bien, se dignará avisarme si debo adquirirla y tenerla por suya 22 .

* * * *

[Salamanca, 13 de abril de 1790]

Mi venerado favorecedor:

Después de un dia de detención en el Escorial, he continuado mi camino, trayendo desde Guadarrama un tiempo deshecho que ha continuado hasta ahora. Los campos estaban generalmente buenos y sólo se echaba menos la hierba y pasto, singularmente en esta tierra que es de muchos ganados. Pe-

(22) Un pliego en $4 . \therefore$. Autógrafa, 
ro ha llovido tanto, tan oportunamente que todo está socorrido y ya desde Peñaranda noté que bajaban los granos. No hay sin embargo que esperar gran baratura, pues aunque hay muchos, la suerte de las cosechas es siempre dudosa, y siempre venden los que no pueden esperar más, los gruesos propietarios y los depósitos públicos tendrán, si no me engaño, gran descalabro.

He abierto la visita del Colegio de Calatrava y voy preparando la salida de los encargos menores de mi comisión. Entre tanto, reconozco esta ciudad y trato a muchos profesores de la Universidad, entre quienes hallo más extendido de lo que pensaba el gusto de los buenos estudios.

Deseo que Vm. se halle aliviado de su fluxión y se mantenga bueno. Saludo a las señoritas y a Sabino, a quien el Padre Maestro Díaz hace mil expresiones. Otras tantas al buen Conde de Isla, al Padre Cuenca, y Vm. disponga como pueda del más fino y sincero amigo suyo,

\section{Salamanca, 13 de abril de $1790^{23}$}

Gaspar de Jovellanos

Carta de Jovellanos a Campomanes. Madrid, 24 agosto 1790. Véase BAE, 86, p. 168, $a b$.

Mi venerado amigo y Señor:

No pudiendo dudar ni de la buena amistad de Vm., ni del sincero interés que toma en mi bien, le retribuyo las más finas gracias, no tanto por la enhorabuena con que me honra cuanto por sus buenos y sabios consejos que conozco dictados por los mismos principios y puedo asegurar a Vm. no sólo que procuraré seguirlos si no que si $V m$. me lo permite, recurriré en la ocasión a buscar los que su superior talento y larga experiencia de negocios pueda comunicarle.

Entretanto renuevo a Vm. la seguridad de mi buen afecto y en fe de él me repito suyo de corazón fino amigo y reconocido servidor que S. M. B.,

$$
\text { G. D. J. }
$$

San Lorenzo y 25 de Nov. de $1797^{24}$.

(23) 1 pliego en $4 \%^{\circ}, 2$ hojas útiles. Autógrafa. Nótese el cambio en el tratamiento.

(24) 1 pliego en $4 .^{\circ} 2$ hojas útiles. Letra de un amanuense. Firma autógrafa. 
$E x^{m o} S^{o r}$ :

En consulta de 17 de julio de este año ha hecho presentes a S. M. la Cámara de Indias, los fundamentos que la mueven a opinar que para que los Obispos electos de aquellos dominios puedan consagrarse en España, no basta que S. M. dispense la Ley civil que prohíbe su consagración en estos Reynos, y que se requiere para ello la intervención y dispensa de su Santidad.

Remito a V. E. de orden del Rey la expresada consulta y la respuesta de los dos fiscales del referido Consejo con copia de un dictamen dado también sobre el mismo asunto para que convocando a su posada al Fiscal de la Cámara de Castilla Dn. Benito Hermida, y a el del Consejo y Cámara de Indias D. Ramón de Posada, examinen este punto, y propongan a S. M. su parecer, a cuyo fin, aviso con esta fecha a Hermida y Posada para que concurran cuando V. E. los convoque.

Dios guarde a V.E. $m^{s} a^{s}$. Palacio, 20 Dic. de $1797^{25}$.

Gaspar de Jovellanos

(25) Un pliego en $4{ }^{\circ}$. Sólo una hoja recto y verso útil. Unicamente la firma es autógrafa. F. U. E. - Fondo Carmen Dorado, 17 - 4. 